\title{
Using geographical information systems to analyse accessibility to health services in the West Bank, Occupied Palestinian Territory
}

\author{
L. Eklund ${ }^{7}$ and U. Mårtensson ${ }^{7}$
}

$$
\text { لينا يكلوند، الريق مارتينام المعلومات الجغر افية لتحليل مدى الوصول إلى الخدمات الصحية في الضفة الغربية، فلسطين المحتلة }
$$

الخلاصـة: يُعَد الوصول إلى الخدمات الصحية الكافية من الحقوق الأساسية للإنسان، إلا أن الحمو اجز ونقاط التفتيش التي يقيمها الاحتلال الإسر إئيلي

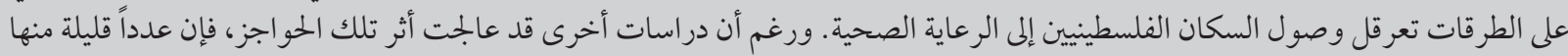

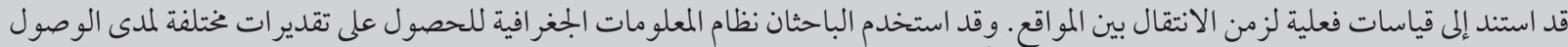

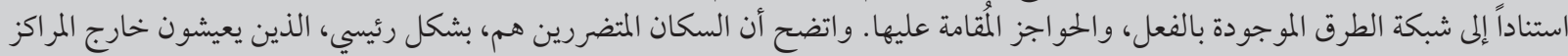

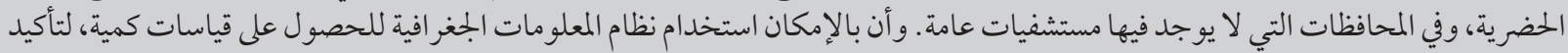

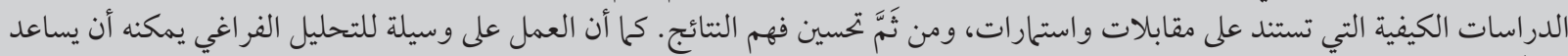

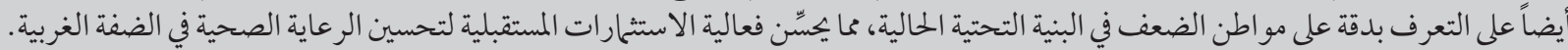

ABSTRACT Accessibility to adequate health services is a basic human right. Israeli road blocks and checkpoints inhibit access to health care for the Palestinian population. While other studies have dealt with the impact of the barriers, few are based on actual measurements of transport times between locations. Geographical information systems (GIS) and network analysis were used to generate different estimations of accessibility based on the existing road network and transport barriers. The population negatively affected were mainly people living outside urban centres and in governorates with no general hospital. Quantitative measurements using GIS can be used to confirm qualitative studies based on interviews and questionnaires and improve the understanding of the results. Working with a spatial analysis tool also helps to pinpoint weaknesses in the current infrastructure, thus improving the efficiency of future investments to improve health care in the West Bank.

Utilisation des systèmes d'information géographique pour analyser l'accessibilité aux services de santé en Cisjordanie (Territoire palestinien occupé)

RÉSUMÉ L'accessibilité aux services de santé appropriés représente un droit humain fondamental. Les barrages routiers et les points de contrôle israéliens entravent l'accès aux soins de la population palestinienne. Alors que d'autres études ont évalué l'impact des barrages, les recherches mesurant le temps de transport réel entre les différents lieux sont rares. Les systèmes d'information géographique et l'analyse du réseau ont été utilisés pour générer des estimations différentes d'accessibilité reposant sur le réseau routier existant et les barrages pour les transports. La population souffrant de difficultés d'accès était celle vivant à l'extérieur des centres urbains et dans des gouvernorats sans hôpital général. Des mesures quantitatives à l'aide des systèmes d'information géographique peuvent être utilisées pour confirmer les études qualitatives reposant sur des entretiens et des questionnaires et pour améliorer l'interprétation des résultats. L'utilisation d'un outil d'analyse spatiale permet aussi de souligner les faiblesses de l'infrastructure en place et de renforcer ainsi l'efficacité des futurs investissements pour améliorer les soins de santé en Cisjordanie.

${ }^{1}$ GIS Centre, Department of Physical Geography and Ecosystem Sciences and Lund University Centre for Middle Eastern Studies, University of Lund, Lund, Sweden (Correspondence to U.Mårtensson: ulrik.martensson@nateko.lu.se).

Received: 30/03/11; accepted: 31/05/11 


\section{Introduction}

Accessibility to health services is not only an important factor for a wellfunctioning society but is even a basic human right. Palestine is considered to have among the best health care in the Eastern Mediterranean Region [1-3]. However, accessibility to all civil services, particularly in Gaza, has deteriorated since 1993, one main reason being the restrictions imposed by the Israeli authorities on travelling between different areas $[1,4]$. The obstacles are of 4 types: checkpoints, separation barriers, road gates and other barriers (Figure 1) [5]. The government of Israel has stated that the obstacles are imposed for security reasons [6]. The movement restrictions are, however, in conflict with the Universal Declaration Human Right, article no. 13, which states that: "Everyone has the right to freedom of movement and residence within the borders of each state" [7].

Studies have shown that a major factor in the utilization of health services is travel time and Bosanac et al. defined travel times exceeding 30 minutes as unacceptable [8]. The Palestinian Central Bureau of Statistics (PCBS) reported on access times to health care before and during the second intifada in 2003 [9]. Before the intifada, $99.3 \%$ of the rural population had a travel time of $<1$ hour to health services, while during the intifada only 91.6\% had < 1 hour. In the West Bank the number of people travelling $<1$ hour for health care decreased from $99.1 \%$ to $93.8 \%$. Evidence of problems related to health care access are manifested in many ways, such as childbirth taking place on the way to the hospital $[10,11]$ and even deaths directly attributable to delays caused by checkpoints and barriers [12]. In a study about the armed conflict's effect on emergency health care, patients at 3 hospitals in the West Bank answered a questionnaire about their hospital route (distance, transportation time, means of transportation and delay) [13]. Two kinds of delay were identified, delays related to the conflict (e.g. checkpoints, curfews and detours) and other delays (e.g. traffic congestion). Of 2228 people who contacted the 3 hospitals during this time, 18\% reported conflict-related delays.

Despite these concerns, and the evidence that accessibility to health services has deteriorated, with in some cases lethal consequences, there are no studies using geographical information systems (GIS) that quantitatively estimate the effects of road closures and barriers on travel time for the general public in Palestine. This study aimed to estimate the current accessibility to health services in the West Bank, and to compare the present situation with a best- and a worst-case scenario in order to quantify the impact of Israeli policies on the Palestinian population. The study focused on accessibility by private car.

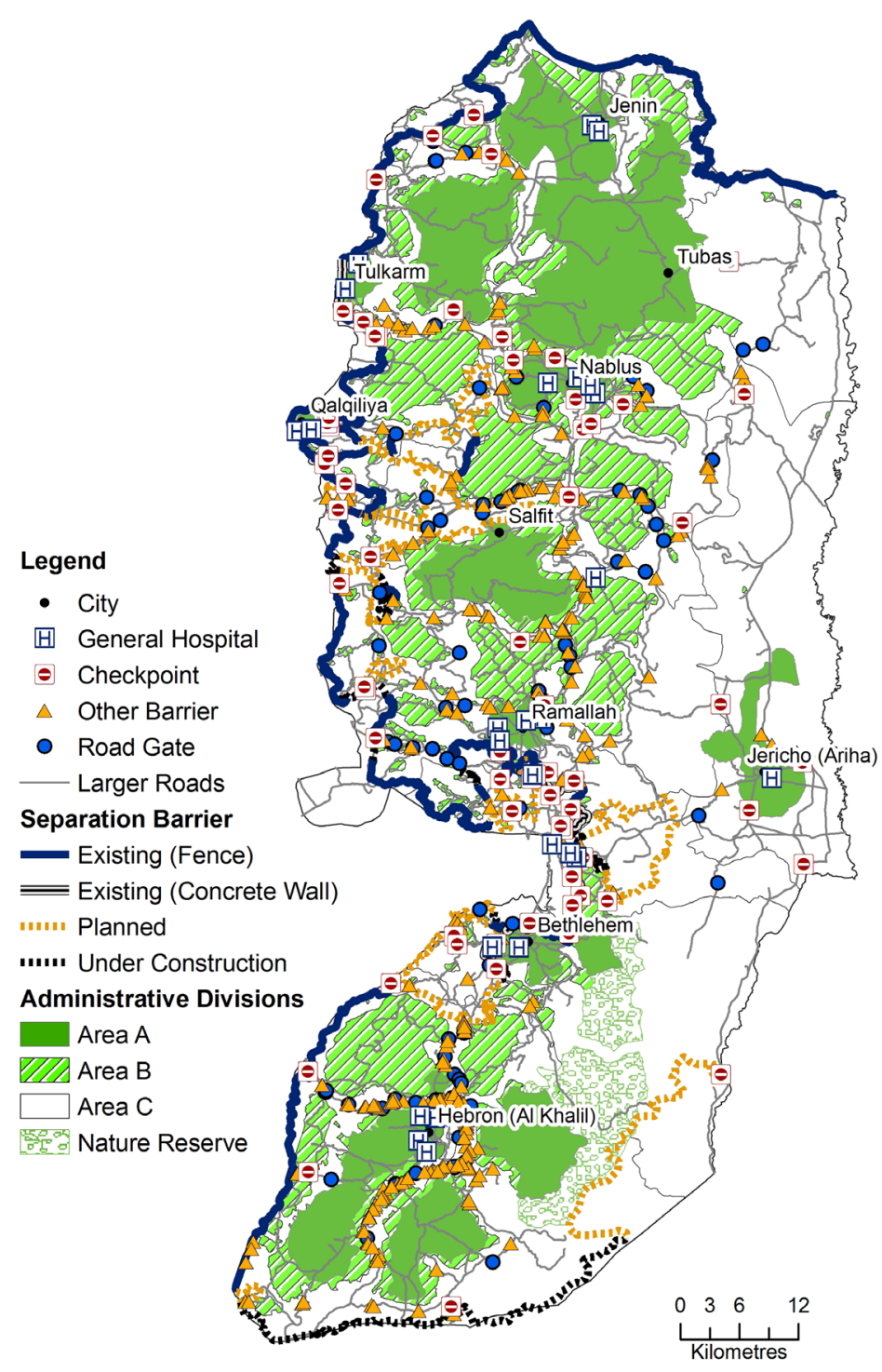

Figure 1 Map showing the West Bank and its geopolitical situation. Main cities are displayed along with the road system (excluding secondary roads). Israeli physical obstructions are classified into 4 main categories: checkpoints, other barriers, road gates and the Israeli separation barrier. The administrative areas from the Oslo Peace Accords are shown in the background 


\section{Methods}

\section{Data and methodology}

GIS data were collected from the GIS database of the Applied Research Institute Jerusalem during an internship in late 2009. Original databases were updated and information added in order to fit the purpose of this study.

Field data collection of road speeds and delay at checkpoints was conducted. To get values for average road speeds, the momentary speed was collected from 530 points distributed in the whole West Bank and connected to the different road types: main roads, main urban roads, regional roads, secondary roads and "internal" roads that included roads within a city or village. For each road type, the average speed was calculated as follows: main road 85 $\mathrm{km} / \mathrm{h}$; main urban road $59 \mathrm{~km} / \mathrm{h}$; regional road $80 \mathrm{~km} / \mathrm{h}$; secondary road $30 \mathrm{~km} / \mathrm{h}$; and internal road $46 \mathrm{~km} / \mathrm{h}$.

To obtain information about delays at checkpoints, interviews were conducted with local people and inquiry forms were handed out in the municipalities of Salfit, Tubas, Al Ram and at the ministry of local government based in Ramalla. A total of 70 interviews were conducted and $59 \mathrm{com}$ pleted inquiry forms were obtained. The respondents were asked about the shortest and the longest delays ever experienced. The resulting delay data from the respondents varied between 0 and 1080 min for long delays, with a concentration of responses between 0 and $360 \mathrm{~min}$. For short delays, the responses varied between 0 and $90 \mathrm{~min}$, but with the majority of responses between 0 and $30 \mathrm{~min}$. The mean shortest delay when summarizing the 129 answers was computed to $15 \mathrm{~min}$ and this was used as standard delay time when possible, but also different delays (0-30 min in 5-min increments) were added to the model to demonstrate the influence of checkpoints on total travel time.
From the roads layer, a network database was built with information about distance, average speeds and checkpoint locations. The network was analysed with the network analyst extension tool of ArcGIS, version 9.2 software. Two analyses were conducted:

- service area analysis, which calculated travelling times to a general hospital for all of the West Bank area. This analysis did not allow for inclusion of possible delays at checkpoints, but did include all changes in travel route (detours) forced by barriers and road closures (including checkpoints).

- closest facility analysis, which calculated in distance and travel time to general hospitals for all of the 668 West Bank communities. In this analysis both detours and delays at checkpoints were included and several analyses with different delay times were done.

For the analyses, 3 scenarios were defined:

- scenario 1: a worst-case scenario, with all checkpoints, road gates and barriers closed. This is likely to happen in times of disturbances.

- scenario 2: the present-day scenario, where all checkpoints are passable, but with a risk of delay, most road gates are open and all other barriers are impassable. When it was possible to include delays at checkpoints (closest facility analysis), 15 min was assumed for the generation of the results.

- scenario 3: a best-case scenario in which there are no obstacles to mobility.

The accessibility estimates were divided in 4 categories to improve the interpretability of the results. An accessibility of $<15$ minutes was classified as good, between 15 and 30 minutes as intermediate, between 30 and 60 minutes as bad and $>60$ minutes as very bad.

\section{Results}

The service area analysis demonstrated that for scenario 1 a large part of the West Bank had bad accessibility, with more than $30 \mathrm{~min}$ travel time to a general hospital (Figure 2). The travel time for this scenario ranged from 1 to $81 \mathrm{~min}$, with the larger cities having a travel time of less than $10 \mathrm{~min}$. For scenario 2 , representing the present situation, both the intermediate areas as well as the good accessibility areas were extended. It is important to note that no delays at checkpoints were included in this analysis. Scenario 3 shows a situation where most people had good or intermediate access to general hospitals. The travel times ranged from 1 to $42 \mathrm{~min}$. In this scenario, the bad accessibility areas could not be explained only by security issues, but by limitations in the road network (which are of course dependent on the political situation and Israeli policy).

The closest facility analyses resulted in accessibility values for each community in the West Bank. For scenario 2, 48 communities (25084 people, $1 \%$ of the total population in the West Bank) had no route to a hospital, but when removing the mobility obstacles (scenario 3 ) there were only 5 communities without a route to a general hospital. An estimated 284915 people (12\% of the total population) had to pass at least 1 checkpoint when going from their home to the closest general hospital. Salfit governorate had a route in which 2 checkpoints was passed, namely the route between Deit Ballut and UNRWA Qalqilia hospital.

In Table 1, the accessibility values for each governorate are presented along with the number of general hospitals, checkpoints and barriers in the governorate. For scenario 2, $15 \mathrm{~min}$ delay was assumed at all checkpoints. The table shows that Bethlehem had 


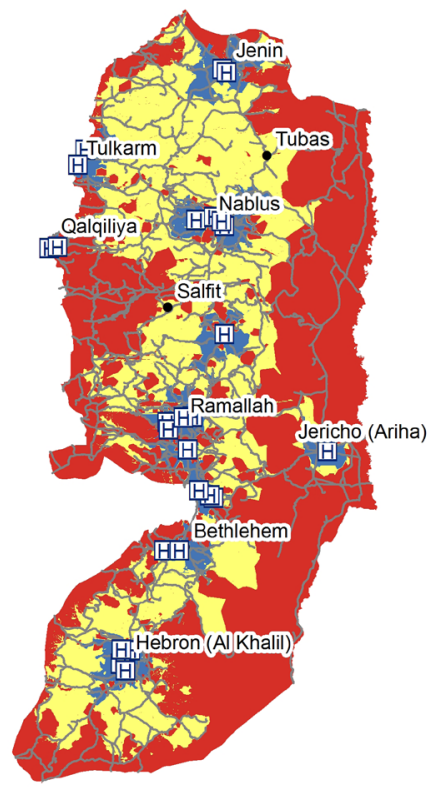

Scenario 1 - Worst Case

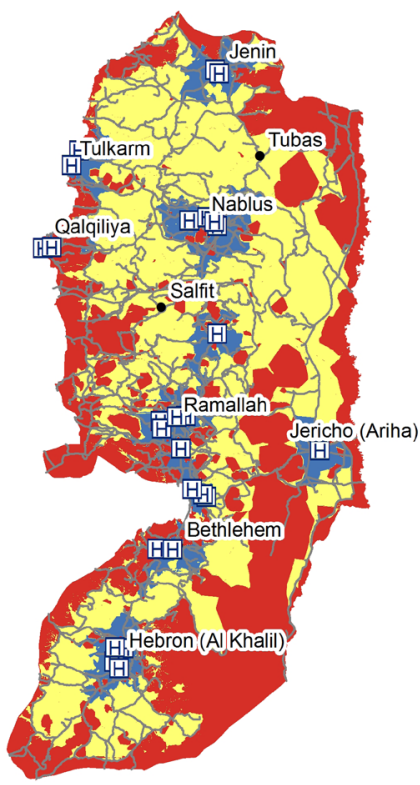

Scenario 2 - Present Situation

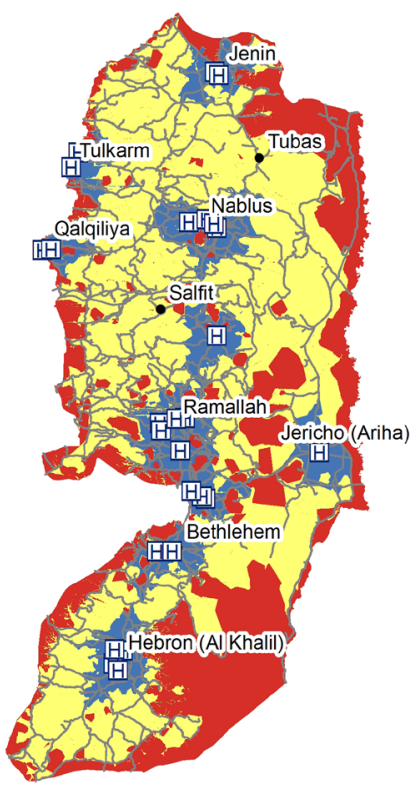

Scenario 3 - Best Case

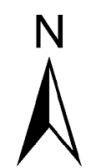

Legend

田 General Hospital

- City

- Larger Roads

Acc. to General Hospitals

$<15 \mathrm{~min}$

$15-30 \mathrm{~min}$

$>30 \mathrm{~min}$

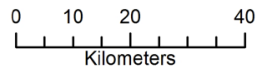

Figure 2 Result from service area analysis (scenario 1 = all checkpoints, road gates and barriers closed; scenario 2 = all checkpoints and some road gates open but barriers closed; scenario 3 = all checkpoints, road gates and barriers removed)

only 2 min difference in average travel time comparing scenario 2 and 3. In Salfit, however, the difference was 20 min, which indicates that the physical obstructions were increasing travel times. The longest time to a general hospital, assuming a 15-min delay at checkpoints, was in Salfit governorate, where the village of Deir Ballut had over $60 \mathrm{~min}$ to a general hospital. For scenario 2 the mean travel time for all communities in Salfit was 40 min; with scenario 3 , the mean time was $20 \mathrm{~min}$
Figure 3 shows the population divided into 4 groups: good, intermediate, bad and very bad accessibility. It shows how the proportions change between scenarios. The results can be interpreted as follows: in a situation with 15 min delay at each checkpoint

\begin{tabular}{|c|c|c|c|c|c|c|c|c|c|}
\hline \multirow[t]{3}{*}{ Governorate } & \multirow{3}{*}{$\begin{array}{l}\text { Area } \\
\mathrm{km}^{2}\end{array}$} & \multirow{3}{*}{$\begin{array}{c}\text { Checkpoints } \\
\text { No. }\end{array}$} & \multirow{3}{*}{$\begin{array}{c}\text { Barriers } \\
\text { No. }\end{array}$} & \multirow{3}{*}{$\begin{array}{c}\text { General } \\
\text { hospitals } \\
\text { No. }\end{array}$} & \multicolumn{5}{|c|}{ Time to general hospital (min) } \\
\hline & & & & & \multicolumn{3}{|c|}{ Scenario 2} & \multirow{2}{*}{$\begin{array}{l}\text { Scenario } 3 \\
\text { Mean }\end{array}$} & \multirow{2}{*}{$\begin{array}{l}\text { Difference between } \\
\text { scenarios } 2 \text { and } 3\end{array}$} \\
\hline & & & & & Mean & Max. & Min. & & \\
\hline Bethlehem & 608 & 7 & 37 & 2 & 12 & 30 & 2 & 10 & 2 \\
\hline Hebron & 1068 & 4 & 111 & 4 & 20 & 53 & 3 & 16 & 4 \\
\hline Jenin & 573 & 3 & 14 & 2 & 16 & 39 & 1 & 15 & 1 \\
\hline Jericho & 609 & 5 & 9 & 1 & 22 & 46 & 2 & 13 & 9 \\
\hline Jerusalem & 354 & 17 & 54 & 4 & 17 & 38 & 0 & 8 & 9 \\
\hline Nablus & 614 & 8 & 37 & 4 & 18 & 38 & 2 & 11 & 7 \\
\hline Qalqiliya & 174 & 6 & 37 & 2 & 29 & 44 & 2 & 11 & 18 \\
\hline Ramallah & 849 & 7 & 85 & 5 & 18 & 49 & 2 & 13 & 5 \\
\hline Salfit & 202 & 4 & 28 & 0 & 40 & 60 & 24 & 20 & 20 \\
\hline Tubas & 366 & 1 & 4 & 0 & 26 & 46 & 11 & 25 & 1 \\
\hline Tulkarm & 245 & 5 & 30 & 2 & 14 & 23 & 0 & 11 & 3 \\
\hline West Bank average & 515 & 6 & 41 & 2 & 21 & 42 & 4 & 14 & 7 \\
\hline
\end{tabular}

Scenario 1 = all checkpoints, road gates and barriers closed; scenario 2 = all checkpoints and some road gates open but barriers closed; scenario 3 = all checkpoints, road gates and barriers removed. 


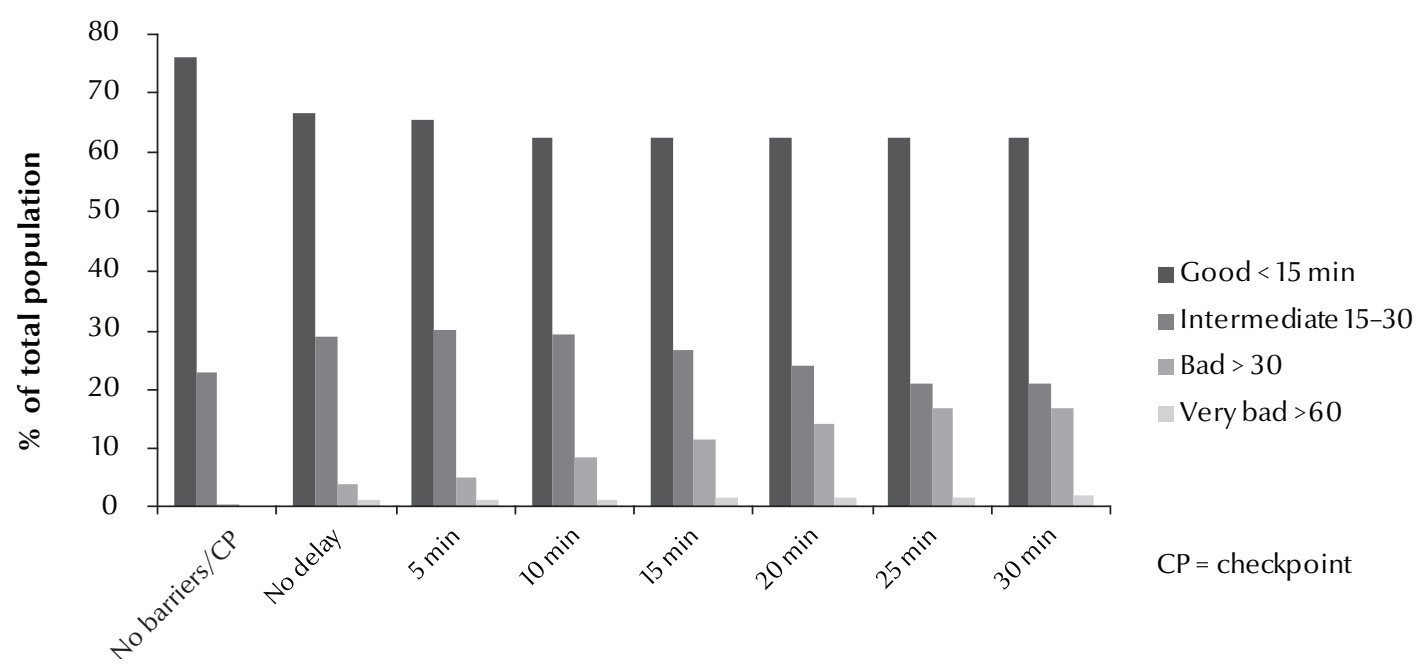

Figure 3 Chart showing how the accessibility situation for the West Bank population changes when adding checkpoints, road gates and barriers and increasing delay at checkpoints

(scenario 2), almost $40 \%$ of the West Bank population had more than 15 min to the nearest general hospital. Of these, approximately $25 \%$ had less than 30 min while over $10 \%$ had more than 30 min. A small percentage even had over $60 \mathrm{~min}$ to a general hospital. Scenario 1, with no checkpoints or barriers, shows a situation in which almost the whole West Bank population had less than 30 min to a general hospital. With a delay of 30 min or more, almost $20 \%$ of the population were included in the bad or very bad accessibility group. However, for all scenarios, the group with good accessibility was never below $60 \%$ of the population.

\section{Discussion}

Vector analysis was chosen for this study rather than raster analysis because of the properties of the West Bank road network. It is not common to drive off road, mainly because of the difficult terrain and also because of the Israeli restrictions on population movements. Terrain properties were not included in the network analysis, which is a source of errors, but this was assumed to be a marginal problem that would not affect the results significantly. This is supported by Eklund who could not find any relationship between travel time to hospital and topography [14]. Including a terrain model in the GIS analysis would take more time with little benefit in terms of accuracy.

The collection of data on delay at checkpoints was not very detailed and the questions could have been interpreted in different ways. One problem is whether the respondents answered with a current delay time or with the highest ever experienced, for example during intifadas. Assumptions were made, however, that the responses for long and short delays were realistic, and that the shortest delay was related to congestions and short interrogations, while the longer delay would be related to detentions or extreme traffic congestions. The risk of errors in the analysis due to the small sample of respondents was marginal since the resulting data were only used to provide a rough estimate of the situation and to get a range between which times the delay should be modelled.

When looking closer into the GIS analysis it becomes clear that the majority of the population were not that affected by the road closures and checkpoints, since they did not have to pass any checkpoint to reach a general hospital and the travel times depended mainly on distance and road speed. This also means that the cases where people did have bad or very bad access were most often related to the obstructions (including checkpoints), independent of other factors such as road quality and speed limits. Whether or not there was a hospital in the governorate was critical for accessibility, not only due to longer distances but also since the checkpoints generally were situated between governorates. The people affected were mainly in smaller villages, far from the cities. Figure 3 show that the number of affected people increased when introducing checkpoints and barriers, supporting the statement that the road closures and checkpoints were an important reason for high travelling times. This was not only caused by the delay at checkpoints, but also by the detours that were forced by barriers, closed roads and the separation wall. The impact of detours is easier to assess than the impact on travel times caused by checkpoints because of the irregular system of interrogation at checkpoints.

Regarding the scenarios set up for this paper, both 1 (total closure) and 2 
(checkpoints and crossings selectively open) are today a reality, while scenario 3 represents a possible future. It could be discussed whether the scenarios are realistic or not, since the actual situation is fluctuating on a day-to-day basis, depending even on such banal factors such as the staff manning checkpoints. For Palestinians in need of health care, this may be the most stress generating factor: that they cannot actually ever be sure of when, or even if, they are going to get to hospital.

It has been demonstrated in this paper that although many studies dealing with accessibility already exist, almost all of them were based on interviews and questionnaires, and not on measurements of access time but rather on perceptions of access time, which could be different. Very few maps illustrating the situation can be found (one example is from the United Nations Office for the Coordination of Humanitarian Affairs/World Health Organization [15]) and even fewer are based on actual measurements or model results for access time. In most cases they show a static situation, such as areas affected by the construction of the barrier, location of checkpoints, etc. At most the affected population or areas were listed or summed in a table. It is interesting to see that there was strong agreement between these 2 approaches; as an example the PCBS has stated that before the second intifada $99 \%$ of the population had $<1$ hour travel time to the nearest hospital or health care centre and the travel time analysis done in this paper implies that 99\% of the population had $<1$ hour travel time (scenario 2, most relevant for the pre-intifada period) [9]. However, during the intifada, PCBS stated that approximately $94 \%$ of the population had less than 1 hour travel time [9] while the GIS analysis implies that about $98 \%$ of the population have less than 1 hour travel time if the traveller is forced to wait $30 \mathrm{~min}$ at a checkpoint. The difference is interesting but the explanation not obvious. It could be because actual waiting times at the checkpoints were underestimated in the GIS analysis or actual travel times were overestimated by the people responding to the questionnaires. There might be other reasons; what is important is that the 2 approaches complement each other, and whenever differences are detected, they should be a reason for further examination.

\section{Conclusions}

The findings of this paper show that accessibility to health care of the Palestinian West Band population is highly dependent on Israeli road closures and checkpoints, where approximately 285000 people have to pass by at least 1 checkpoint on the way to a general hospital. Intraregional accessibility is less restricted than interregional, and presence of a general hospital in the governorate is highly critical. Most affected are the rural populations, living far from city centres where most general hospitals are located because they are obliged to pass checkpoints and/or make detours on their way to hospital. For people living in the main urban centres the negative effect is much less pronounced, mainly because the checkpoints are seldom built inside a Palestinian town.

The approach using GIS tools has been found to be a good complement to the existing, more qualitative, information collection that has often been the main way of examining accessibility to health care. By combining qualitative and quantitative approaches it is possible to get a more objective picture of accessibility. An interesting way forward could be to improve the comparisons to further develop understanding regarding measured physical and experienced mental distances. The former could be used as an independent variable to improve understanding and validate issues difficult to explain and define such as anxiety, stress and the general sense of being unable to affect your life situation.

The obvious conclusion from this study is that, apart from the distance from their home to the nearest general hospital (measured as travel time), the road closures and checkpoints delay the Palestinian population from access to health services and mainly so in rural environments. The results also imply that, since the Palestinian-Israeli conflict is likely to continue during the foreseeable future, the Palestinian $\mathrm{Au}$ thority has to use accessibility studies as outlined in the present paper to be able ensure acceptable health service access times for the entire population. Using GIS will enable investments to be prioritized based on actual conditions and thus be more relevant for improving conditions.

It is important to note that the resulting accessibility models are only assessments and can never completely describe the complexities of the situation on the ground. The accessibility situation in the West Bank is changing from day to day and this model does not aspire to provide answers on exactly how long time it will take to reach a hospital. This would require a constantly updated database on the checkpoint locations and delays. The purpose of the study was to be a complement to more qualitative studies and a new approach that might be less dependent on respondent errors. Furthermore, the results provide some statistics about how many people are affected by bad accessibility and indications about which areas are most affected. 


\section{References}

1. Giacaman R et al. Health in the occupied Palestinian territory 1: Health status and health services in the occupied Palestinian territory. Lancet, 2009, 373:837-849.

2. Rajaratnam J et al. Neonatal, postneonatal, childhood, and under-5 mortality for 187 countries, 1970-2010: a systematic analysis of progress towards Millennium Development Goal 4. Lancet, 2010, 375:1988-2008.

3. Hogan M et al. Maternal mortality for 181 countries, 19802008: a systematic analysis of progress towards Millennium Development Goal 5. Lancet, 2010, 375:1609-1623.

4. Four years-Intifada, closures and Palestinian economic crisis: an assessment. Jerusalem, World Bank, 2004.

5. West Bank movement and access update: May 2009. Jerusalem, United Nations Office for the Coordination of Humanitarian Affairs, 2009, (http://unispal.un.org/UNISPAL.NSF/0/ B3EDBB76DAFDDD6A852575C20065E305, accessed 18 June 2012).

6. The humanitarian impact on Palestinians of Israeli settlements and other infrastructure in the West Bank, Jerusalem, July 2007. Jerusalem, United Nations Office for the Coordination of Humanitarian Affairs-Occupied Palestinian Territory, 2007.

7. The Universal Declaration of Human Rights. New York, United Nations. 1948 (http://www.un.org/en/documents/udhr/ index.shtml\#a13, accessed 18 June 2012).

8. Bosanac E, Parkinson R, Hall D. Geographical access to hospital care: a 30-minute travel time standard. Medical Care, 1976 14(7):616-624.

9. Access to health service survey-2003: main findings. Ramalla, Palestinian Central Bureau of Statistics, 2003.
10. Wick L. Birth at the checkpoint, the home or the hospital? Adapting to the changing reality in Palestine. Ramalla, Institute of Community and Public Health, Birzeit University, 2002 (http://icph. birzeit.edu/uploads/File/monographs/2002\%20Birth\%20 at\%20the\%20checkpoint $\% 202002$.pdf, accessed 18 June 2012).

11. Giacaman R, Abu-Rmeileh N, Wick L. The limitations on choice: Palestinian women's childbirth location, dissatisfaction with the place of birth and determinants. European Journal of Public Health, 2006, 17(1):86-91.

12. Palestinians who died following an infringement of the right to medical treatment in the Occupied Territories 2008. B'tselem [online factsheet], (http://www.btselem.org/English/Statistics/Casualties_Data.asp?Category=21\&region=TER, accessed 18 June 2012).

13. Rytter $\mathrm{M}$ et al. Effects Of armed conflict on access to emergency health care in Palestinian West Bank: systematic collection of data in emergency departments. British Medical Journal, 2006, 332:1122-1124.

14. Eklund L. Accessibility to health services in the West Bank, Occupied Palestinian Territory. Lund, Sweden, University of Lund, 2010 (Seminar Series No. 189).

15. Health facilities map 2-as of 2004. Ramalla, United Nations Office for the Coordination of Humanitarian Affairs/World Health Organization, 2005 (http://www.ochaopt.org/documents/WB_Health_CAP2006.pdf, accessed 28 June 2012). 